ASTHMA AND THE ENVIRONMENT

\title{
Asthma symptoms in women employed in domestic cleaning: a community based study
}

\author{
M Medina-Ramón, J P Zock, M Kogevinas, J Sunyer, J M Antó
}

Thorax 2003;58:950-954

See end of article for authors' affiliations

.....................

Correspondence to: Drs J M Antó and J P Zock, IMIM, Dr Aiguader 80, E-08003 Barcelona, Spain; imanto@imim.es

Received 30 January 2003 Accepted for publication 19 July 2003
Background: Epidemiological studies have shown an association between cleaning work and asthma, but the risk factors are uncertain. The aim of this study was to assess the risk of asthma in women employed in domestic cleaning.

Methods: A cross sectional study was conducted in 4521 women aged 30 to 65 years. Information on respiratory symptoms and cleaning work history was obtained using a postal questionnaire with telephone follow up. Asthma was defined as reported symptoms in the last year or current use of drugs to treat asthma. Odds ratios (OR) with $95 \%$ confidence intervals (Cl) for asthma in different cleaning groups were estimated using adjusted unconditional logistic regression models.

Results: 593 women (13\%) were currently employed in domestic cleaning work. Asthma was more prevalent in this group than in women who had never worked in cleaning $1 \mathrm{OR} 1.46(95 \% \mathrm{Cl}, 1.10$ to 1.92)). Former domestic cleaning work was reported by 1170 women (26\%), and was strongly associated with asthma (OR 2.09 (1.70 to 2.57)). Current and former non-domestic cleaning work was not significantly associated with asthma. Consistent results were obtained for other respiratory symptoms. Twenty five per cent of the asthma cases in the study population were attributable to domestic cleaning work.

Conclusions: Employment in domestic cleaning may induce or aggravate asthma. This study suggests that domestic cleaning work has an important public health impact, probably involving not only professional cleaners but also people undertaking cleaning tasks at home.
A sthma is the most common occupational lung disease in industrialised countries. ${ }^{1}$ Occupational exposures are estimated to be responsible for $5-20 \%$ of all adult asthma cases ${ }^{2}$ and numerous occupations with increased risk and causative agents have been identified. ${ }^{3}$ Several community based studies have recently shown an increased risk for asthma in cleaners, an occupation not traditionally associated with this disease. ${ }^{4}$ However, the types of exposure associated with asthma in cleaners have not been identified. Analyses within the Spanish centres of the European Community Respiratory Health Survey (ECRHS) suggested that the excess risk for asthma in cleaners occurred mostly in domestic cleaners. ${ }^{6}$ The results of that study, however, were based on a small and selected population sample, and the possible influence of recall bias could not be excluded. No other study has been published assessing the association between employment in domestic cleaning and asthma. If confirmed, an increased risk of asthma in domestic cleaners could be of substantial public health importance as this is a large occupational group and some of their exposures are shared by housewives and other people doing cleaning tasks at home. Studying domestic cleaners is particularly difficult, given the informal nature of this occupation in many countries and the lack of available registries. We carried out a large cross sectional study in a population with an expected high number of domestic cleaners, aiming at assessing the risk of asthma in this workforce.

\section{METHODS}

A cross sectional study was conducted in Cornellà, a city in the metropolitan area of Barcelona, Spain. All female residents between 30 and 65 years of age and with less than eight years of education were identified using the municipal census, and a random sample of 5390 women (37\%) was taken from this selected population. Errors in addresses or in registered age resulted in 270 non-eligible subjects.

Between June 2000 and July 2001 a short questionnaire was sent by mail to all 5120 eligible subjects. Telephone follow up was undertaken for those who did not respond by mail or had important missing data in the postal questionnaire. The participants were not informed about the main study hypothesis (that is, the association between domestic cleaning and asthma).

The questionnaire included symptom questions extracted from the questionnaire used in the ECRHS. ${ }^{7}$ The validity and reliability of these questions have been described elsewhere. ${ }^{8}$ Participants were asked the following:

(a) Had they experienced wheezing with breathlessness in the last 12 months?

(b) Had they experienced wheezing apart from colds in the last 12 months?

(c) Had they ever had asthma? If yes, what was the age of the first asthma attack?

(d) Had they ever been woken by an attack of shortness of breath in the last 12 months?

(e) Had they ever had an attack of asthma in the last 12 months?

(f) Did they take drugs for asthma?

(g) Did they have a regular cough during at least three months each year?

(h) Did they regularly bring up phlegm during at least three months each year?

(i) Did they ever have a problem with sneezing or a runny or a blocked nose when not having a cold or the flu?

(j) Had they ever had respiratory problems related to any job? If yes, had they quit that job? 
Current asthma was defined as an affirmative answer to at least one of questions (d), (e), or (f). ${ }^{4}$ Adult onset asthma was defined as an affirmative answer to (c), with the first attack of asthma at the age of 15 years or older. Chronic bronchitis was defined as a positive answer to questions (g) or (h). Ever rhinitis was defined as a positive answer to question (i). Work related respiratory symptoms were defined as an affirmative answer to question (j).

Detailed questions about history in cleaning work followed the respiratory symptom questions. Subjects were classified according to timing and type of cleaning work. We distinguished between current (at the time of the interview) and former cleaning work. All women who were paid to clean somebody else's home (including those paid on an hourly or ad hoc basis) were considered to be domestic cleaners. Other paid cleaning workers were regarded as non-domestic cleaners. Women who worked simultaneously in domestic and non-domestic cleaning were included in the domestic cleaning group. Detailed information about the site of nondomestic cleaning work was only requested in current nondomestic cleaners.

\section{Statistical analyses}

Statistical analyses were done using Stata version 6.0 (Stata Corporation, College Station, Texas, USA). Unconditional logistic regression models were used to estimate odds ratios (OR) and 95\% confidence intervals (CI) for each cleaning group and respiratory outcome. All odds ratios were adjusted for age group and smoking status. Women who had never worked in cleaning were used as the reference group.

\section{RESULTS}

Of the eligible sample of 5120 women, questionnaire data were obtained for 4592 subjects (response rate 90\%). No major differences in age or educational level were observed between responders and non-responders. After excluding those with missing data, final analyses were done on 4521 subjects. The mean (SD) age of the women in the study population was 50.7 (9.4) years and most of them had never smoked (table 1). Half the population had been employed in cleaning at some time. Among these, 39\% were working as cleaners at the time of the interview, most in private home cleaning. A minority of the current domestic cleaning women ( $14 \%)$ worked simultaneously as cleaners in a non-domestic site. The large majority $(85 \%)$ of the 1371 former cleaning women had been working in domestic cleaning.

The prevalences of current asthma and chronic bronchitis in the study population were $12.6 \%$ and $15.2 \%$, respectively (table 2). Six per cent reported ever having had asthma, and

Table 1 Characteristics of the study population ( $\mathrm{n}=4521$ )

\begin{tabular}{lll}
\hline Category & $\mathbf{n}$ & $\%$ \\
\hline Age 30 to 39 years & 702 & 15.5 \\
Age 40 to 49 years & 1,150 & 25.4 \\
Age 50 to 59 years & 1,750 & 38.7 \\
Age 60 to 65 years & 919 & 20.3 \\
Never smoked & 3,355 & 74.2 \\
Ex-smokers & 319 & 7.1 \\
Current smokers & 847 & 18.7 \\
Never worked in cleaning & 2,262 & 50.0 \\
Current domestic cleaners* & 593 & 13.1 \\
Current non-domestic cleaners $\dagger$ & 295 & 6.5 \\
Former domestic cleaners & 1170 & 25.9 \\
Former non-domestic cleaners & 201 & 4.4
\end{tabular}

*85 subjects in this category were employed both in domestic and nondomestic cleaning.

†120 subjects in this category had been domestic cleaners in the past.
Table 2 Prevalence of respiratory symptoms $(n=4521)$

\begin{tabular}{|c|c|c|}
\hline Symptoms & $n^{*}$ & $\%$ \\
\hline $\begin{array}{l}\text { Wheezing in the last } 12 \text { months } \\
\text { Wheezing with breathlessness } \\
\text { Wheezing apart from colds } \\
\text { Ever asthma } \\
\text { Childhood onset asthma† } \\
\text { Adult onset asthmat } \\
\text { Current asthma§ } \\
\text { Being woken by an attack of shortness of } \\
\text { breath in the last } 12 \text { months } \\
\text { Attack of asthma in the last } 12 \text { months } \\
\text { Current use of drugs for asthma } \\
\text { Chronic bronchitis } \\
\text { Regular cough at least three months each } \\
\text { year } \\
\text { Regularly bringing up phlegm at least three } \\
\text { months each year } \\
\text { Both the above symptoms } \\
\text { Ever rhinitis } \\
\text { Work related symptoms** }\end{array}$ & $\begin{array}{l}819 \\
503 \\
422 \\
270 \\
43 \\
199 \\
568\end{array}$ & $\begin{array}{l}18.1 \\
11.1 \\
9.3 \\
6.0 \\
1.0 \\
4.4 \\
12.6\end{array}$ \\
\hline \multicolumn{3}{|c|}{$\begin{array}{l}{ }^{*} \text { Missing data for specific symptoms between } 0 \text { and } 42 \text { subjects. } \\
\text { †First attack of asthma at age }<15 \text { years. } \\
\text { \#First attack of asthma at age } 15 \text { years or older. } \\
\S \text { Woken by an attack of shortness of breath in the last } 12 \text { months, or } \\
\text { attack of asthma in the last } 12 \text { months, or current use of drugs for asthma. } \\
\text {-Regular cough at least three months each year, or regularly bringing up } \\
\text { phlegm at least three months each year. } \\
{ }^{*} \text { Respiratory problems caused by any job. }\end{array}$} \\
\hline
\end{tabular}

$74 \%$ of these had their first asthma attack at the age of 15 years or older.

Those reporting ever having worked as cleaners showed an excess risk for all respiratory outcomes under study in comparison with those who had never worked as cleaners (table 3). Risks in former cleaners were slightly higher than in current cleaners. Domestic cleaning was consistently associated with all respiratory symptoms. Increased risks of both current asthma and chronic bronchitis were observed in current domestic cleaners (OR 1.46 (95\% CI, 1.10 to 1.92) and 1.61 (1.25 to 2.06), respectively) and in former domestic cleaners (OR 2.09 ( 1.70 to 2.57 ) and 1.67 (1.37 to 2.02), respectively). Non-domestic cleaners did not show any statistically significant risk, although for some symptoms non-significantly increased risks were observed in former non-domestic cleaners. The same pattern was observed for all other respiratory symptoms not shown in table 3. When analyses were repeated defining chronic bronchitis as regular cough with phlegm, the odds ratios were very similar. Furthermore, when subjects reporting asthma and chronic bronchitis simultaneously were excluded from the analyses, asthma and chronic bronchitis risks did not change substantially. Additional adjustment for educational level yielded essentially similar risk estimates as those presented in table 3.

The prevalence rate of work related respiratory symptoms was $12 \%$ for women who had ever worked as cleaners, and $5 \%$ for women who had never worked in cleaning (results not shown). The proportion of former cleaners reporting having quit the cleaning job because of work related symptoms was $1.3 \%$. When analyses were repeated excluding those who had quit any job because of respiratory problems, former cleaners still presented a higher risk for asthma (OR 1.83 (95\% CI, 1.48 to 2.26 )) than current cleaners (OR 1.35 (95\% CI, 1.04 to $1.74))$.

Current asthma and chronic bronchitis risks in current domestic cleaners were stratified by potential effect modifiers (table 4). The risk of chronic bronchitis was significantly higher for smokers than for non-smokers (interaction $\mathrm{p}<0.05)$. Both asthma and chronic bronchitis risks decreased with increasing age, the difference between the lower and the 
Table 3 Association between type and timing of cleaning work and selected respiratory symptoms

\begin{tabular}{|c|c|c|c|c|c|}
\hline & $\begin{array}{l}\text { Wheezing with } \\
\text { breathlessness }\end{array}$ & Ever asthma & Current asthma* & Chronic bronchitis† & Ever rhinitis \\
\hline Ever worked in cleaning & 1.53 (1.27 to 1.85$)$ & 1.44 (1.12 to 1.85$)$ & 1.73 (1.44 to 2.07$)$ & $1.52(1.29$ to 1.80$)$ & $1.20(1.06$ to 1.35$)$ \\
\hline Current cleaner & 1.37 (1.06 to 1.76$)$ & 1.03 (0.72 to 1.47$)$ & 1.32 (1.04 to 1.69$)$ & 1.41 (1.13 to 1.76$)$ & 1.08 (0.92 to 1.28$)$ \\
\hline Domestic & 1.48 (1.11 to 1.97$)$ & $1.21(0.82$ to 1.79$)$ & $1.46(1.10$ to 1.92$)$ & 1.61 (1.25 to 2.06$)$ & $1.18(0.97$ to 1.42$)$ \\
\hline Non-domestic & $1.17(0.79$ to 1.76$)$ & $0.68(0.35$ to 1.32$)$ & $1.08(0.72$ to 1.61$)$ & $1.08(0.76$ to 1.55$)$ & $0.92(0.71$ to 1.20$)$ \\
\hline Former cleaner & 1.63 (1.32 to 2.02$)$ & $1.68(1.28$ to 2.21$)$ & 2.00 (1.63 to 2.43$)$ & $1.58(1.31$ to 1.90$)$ & 1.27 (1.12 to 1.47$)$ \\
\hline Domestic & $1.69(1.35$ to 2.10$)$ & 1.76 (1.33 to 2.33$)$ & 2.09 (1.70 to 2.57$)$ & 1.67 (1.37 to 2.02$)$ & 1.31 (1.13 to 1.51$)$ \\
\hline Non-domestic & $1.34(0.85$ to 2.11$)$ & $1.22(0.66$ to 2.26$)$ & $1.41(0.91$ to 2.18$)$ & $1.09(0.71$ to 1.66$)$ & $1.11(0.82$ to 1.50$)$ \\
\hline
\end{tabular}

Odds ratios (95\% confidence intervals) relative to those who had never worked in cleaning $(\mathrm{n}=2262)$, adjusted for age category and smoking status

*Woken by an attack of shortness of breath in the last 12 months, or attack of asthma in the last 12 months, or current use of drugs for asthma.

tRegular cough at least three months each year, or regularly bringing up phlegm at least three months each year.

upper age tertile being statistically significant for asthma. Cleaners who worked simultaneously in domestic and nondomestic cleaning had a higher $(\mathrm{p}<0.05)$ asthma risk (OR 2.79 ( $95 \%$ CI, 1.64 to 4.75$)$ ) than those who were exclusively employed in domestic cleaning (OR 1.26 (0.93 to 1.71$)$ ).

Current non-domestic cleaners worked in a wide variety of locations (table 5). The largest category comprising office cleaners did not show an excess risk, either for asthma or for chronic bronchitis. A statistically significant risk for asthma and chronic bronchitis was observed in subjects cleaning in hospitals and other health care centres. Non-significant asthma risks were observed in cleaners working in hotels and residences, laboratories, and kitchens.

\section{DISCUSSION}

This community based study is the first epidemiological investigation specifically designed to assess the risk of asthma in women employed as domestic cleaners. Significantly increased risks for asthma and other respiratory symptoms were found in women currently working as domestic cleaners, as well as in women who had a domestic cleaning job in the past.

The increased asthma risk observed in current domestic cleaners confirms the results obtained in an analysis of a small subsample of the ECRHS. ${ }^{6}$ Consistently, several surveillance programmes ${ }^{9-11}$ and case reports ${ }^{12-14}$ have suggested that exposure to cleaning products is associated with work related asthma in numerous occupations, although no specific reference has been made to domestic cleaning. The observed high prevalence of asthma in current domestic cleaners could be a result of either a net increase of incidence among domestic cleaners or a longer duration of pre-existing asthma. In both situations the occupational exposure is equally relevant as it is well recognised that work related asthma includes both types of case. With the present data we cannot distinguish between these two different patterns of work related asthma. Domestic cleaning workers are exposed to a large variety of cleaning products containing both irritants and sensitisers, as well as to indoor allergens. ${ }^{15}$ Consequently, it can be hypothesised that the onset or aggravation of asthma in domestic cleaners could be related to an irritant induced mechanism or to specific sensitisation.

Former cleaners showed a higher asthma risk than current cleaners. A possible explanation for this finding could be the healthy worker effect-that is, those who get the disease are more likely to leave the job, resulting in an increase in the asthma prevalence in former cleaners and a decrease in current cleaners. This is supported by the fact that the majority of occupational asthma cases fail to recover after removal from exposure. ${ }^{16}$ However, in our study, the percentage of former cleaners who reported having quit the cleaning job owing to respiratory problems was relatively low $(1.3 \%)$. When analyses were repeated excluding subjects who had quit a job because of respiratory problems, former cleaners still had a higher asthma risk than current cleaners. Thus, apart from the healthy worker effect, there are probably other determinants responsible for the difference in asthma risks between former and current cleaners. It can be hypothesised that relevant exposures in cleaners have decreased during the last decades-as also observed in other

Table 4 Association between current domestic cleaning, current asthma and bronchitis, stratified by smoking status, age category, and employment in another cleaning job

\begin{tabular}{|c|c|c|c|c|}
\hline & $\begin{array}{l}\text { Never } \\
\text { cleaners (n) }\end{array}$ & $\begin{array}{l}\text { Current domestic } \\
\text { cleaners (n) }\end{array}$ & Current asthma* & Chronic bronchitis \\
\hline \multirow{8}{*}{$\begin{array}{l}\text { Current non-smokers } \\
\text { Current smokers } \\
\text { Age } 30 \text { to } 46 \text { years } \\
\text { Age } 47 \text { to } 55 \text { years } \\
\text { Age } 56 \text { to } 65 \text { years } \\
\text { Exclusively domestic } \\
\text { cleaning } \\
\text { Domestic and non- } \\
\text { domestic cleaning } \\
\text { simultaneously }\end{array}$} & 1843 & 484 & 1.50 (1.11 to 2.04$)$ & 1.37 (1.02 to 1.85$)$ \\
\hline & 419 & 109 & $1.27(0.65$ to 2.46$)$ & $2.40(1.52$ to 3.80$)$ t \\
\hline & 733 & 199 & $1.96(1.22$ to 3.13$)$ & $1.85(1.25$ to 2.74$)$ \\
\hline & 746 & 243 & $1.46(0.94$ to 2.27$)$ & $1.57(1.02$ to 2.41$)$ \\
\hline & 783 & 151 & $1.00(0.57$ to 1.76$) \S$ & 1.35 (0.83 to 2.20$)$ \\
\hline & & & $1.26(0.93$ to 1.71$)$ & 1.55 (1.19 to 2.02$)$ \\
\hline & & & 2.79 (1.64 to 4.75$)$ & 1.93 (1.13 to 3.29 ) \\
\hline & 2262 & 85 & & \\
\hline
\end{tabular}

Odds ratios (95\% confidence intervals) relative to those who had never worked in cleaning.

*Woken by an attack of shortness of breath in the last 12 months, or attack of asthma in the last 12 months, or current use of drugs for asthma.

tRegular cough at least three months each year, or regularly bringing up phlegm at least three months each year. fDifferent from risk in non-smokers; $p<0.05$ for multiplicative interaction.

§Different from risk in age group 30 to 46 years; $p<0.1$ for multiplicative interaction.

- Different from risk in exclusively domestic cleaners $(p<0.05)$. 
Table 5 Association between location of non-domestic cleaning work, current asthma, and chronic bronchitis

\begin{tabular}{llll}
\hline Location of cleaning work* & $\mathbf{n}$ & Current asthma† & Chronic bronchitis \\
\hline Offices & 124 & $1.0(0.6$ to 1.9$)$ & $0.9(0.5$ to 1.5$)$ \\
Schools and other educational centres & 53 & $0.6(0.2$ to 1.8$)$ & $1.1(0.5$ to 2.4$)$ \\
Hospitals and other health care centres & 34 & $2.5(1.1$ to 5.8$)$ & $2.2(1.0$ to 4.8$)$ \\
Shops and public buildings & 26 & $0.4(0.1$ to 3.0$)$ & $0.6(0.2$ to 2.8$)$ \\
Factories & 19 & $1.2(0.3$ to 5.0$)$ & $0.9(0.2$ to 3.8$)$ \\
Hotels and residences & 18 & $1.9(0.5$ to 6.6$)$ & $1.9(0.6$ to 6.0$)$ \\
Bars and restaurants & 13 & $0(-)$ & $1.3(0.3$ to 5.8$)$ \\
Flat entrances and staircases & 9 & $1.3(0.2$ to 10.5$)$ & $1.9(0.4$ to 9.7$)$ \\
Kitchens & 6 & $2.1(0.2$ to 17.6$)$ & $3.8(0.7$ to 21.1$)$ \\
Sports installations & 6 & $0(-)$ & $1.7(0.2$ to 14.9$)$ \\
Laboratories & 6 & $1.9(0.2$ to 16.7$)$ & $1.1(0.1$ to 9.4$)$ \\
Other locations & 8 & $0(-)$ & $0.9(0.1$ to 7.5$)$ \\
\hline
\end{tabular}

Odds ratios ( $95 \%$ confidence intervals) relative to those who had never worked in cleaning $(n=2262)$, adjusted for age category and smoking status.

* Subjects may appear in more than one category.

†Woken by an attack of shortness of breath in the last 12 months, or attack of asthma in the last 12 months, or current use of drugs for asthma.

$\ddagger$ Regular cough at least three months each year, or regularly bringing up phlegm at least three months each year.

jobs ${ }^{17}$-leading to a different exposure pattern between current and former cleaners.

Taking into consideration the prevalence of women who have ever worked in domestic cleaning (13.1\% in the present and $25.9 \%$ in the past) and the associated asthma risk, it can be estimated that about $25 \%$ of the asthma cases in our study population could be attributed to having a history of domestic cleaning work. This large figure has probably been influenced both by the characteristics of the area where the study population was recruited (an industrial city within a large metropolitan area) and by the sampling scheme. The proportion of domestic cleaning women in the general population is difficult to estimate, given that in most cases domestic cleaning constitutes an informal occupation in which women are self employed and no registries are available. In the Spanish population of the ECRHS, $2 \%$ of the female participants were current domestic cleaners, representing one third of all current cleaners. Using recent data from the National Institute of Statistics in Spain we estimated that approximately $10 \%$ of women over 16 years old worked in cleaning in the year 2000. Cleaning work is probably also a common occupation among women in other countries. According to a recent study, about $5 \%$ of employed Finnish women work in non-domestic cleaning. ${ }^{18}$ In addition, our findings for domestic cleaning might also have implications for people doing cleaning tasks in their own homes. Several studies have found significantly increased risks for asthma and chronic bronchitis in housewives, ${ }^{4} 1920$ and it has been estimated that $5 \%$ of the asthma risk among women could be attributed to household exposures. ${ }^{4}$ In addition, Reilly and Rosenman ${ }^{21}$ showed that exposure to household cleaning agents was among the most frequent environmental causes of non-work-related hospital admissions for asthma.

Our results show that working or having worked as a domestic cleaner was also associated with several respiratory symptoms other than asthma, including chronic bronchitis. The association between domestic cleaning work and chronic bronchitis remained statistically significant in non-smokers, indicating that confounding by smoking did not play an important role. In addition, non-asthmatic domestic cleaners had a significantly increased risk of bronchitis, suggesting that asthma and chronic bronchitis were independent outcomes. Our findings are in agreement with results of a study in which asthmatic cleaners had a significantly higher prevalence of chronic bronchitis than asthmatic office workers. $^{22}$
The association between non-domestic cleaning work and asthma was not clear. The different risk of asthma observed in domestic and non-domestic cleaning workers could be related to qualitative or quantitative differences in the cleaning exposures of the two groups. As non-domestic cleaners worked in a wide variety of different locations, risks were assessed separately for each location. A high asthma risk was found for cleaners in several locations, but estimates were based on small numbers. Only hospital cleaners showed a statistically significant asthma risk, which could partly reflect shared exposures related to asthma in nurses such as latex, disinfectants, and sensitising drugs. This is consistent with findings of a Finnish surveillance study that also found an increased asthma risk for cleaners working in health and social work centres. ${ }^{18}$ A general conclusion from this study was that part of the increased asthma risk observed in several types of non-domestic cleaning workers reflected exposures inherent to the environment where cleaning work was performed.

There are several limitations in our study that should be considered. The study population of our survey was restricted to female subjects in view of the fact that the large majority of domestic cleaning workers in Spain are women. ${ }^{6}$ Furthermore, we cannot exclude the possibility of misclassification of occupational group, for two main reasons. First, many cleaning workers often change their place of work, and those employed in domestic cleaning tend to show intermittence in their employment. Second, it is possible that some domestic cleaning workers did not report their occupation as a result of the informal status of this job. Nevertheless, it can be expected that misclassification was non-differential, which is likely to produce bias towards the null rather than false positive associations. ${ }^{23}$

\section{Conclusions}

Employment in domestic cleaning was found to be associated with asthma, chronic bronchitis, and other respiratory symptoms among Spanish women. These findings are supported by results from several surveillance studies and case reports. The high risk of asthma attributable to domestic cleaning suggests a substantial public health impact, which might be even greater if we take into consideration that housewives and others doing cleaning tasks at home are probably also at risk. Further research is needed to identify the specific exposures responsible for the increased asthma risk in domestic cleaners. 


\section{ACKNOWLEDGEMENTS}

The study was supported by the Spanish Ministry of Science and Technology (grant CICYT/FEDER (2FD97-2071) and partially by ISCIII, Red de Centros RCESP, C0309 and DURSI CSGR 2001-00406). We thank Mercè Martí and the Department of Public Health, Social Services and Women's Affairs from the City Council of Cornellà de Llobregat for facilitating the collaboration of the participants in the study; Natalia Molina, Laura Bouso, Silvia Sarri, and Yolanda Torralba for doing the interviews; and Dave Macfarlane for technical assistance and editing. We are also grateful to Montse Ramos, Neus Moreno, Carme Valls, and Angels Company for their advice in the design of the study, and to all women who generously participated in the study. Finally, we also acknowledge Professor A J NewmanTaylor and Dr Hans Kromhout for their advice on different parts of the study.

\section{Authors' affiliations}

M Medina-Ramón, J P Zock, M Kogevinas, J Sunyer, J M Antó, Respiratory and Environmental Health Research Unit, Municipal Institute of Medical, Research, Barcelona, Spain

J Sunyer, J M Antó, Department of Experimental and Health Sciences, Pompeu Fabra University, Barcelona

\section{REFERENCES}

1 Venables KM, Chang-Yeung M. Occupational asthma. Lancet 1997;349:1465-9.

2 Blanc PD, Toren K. How much adult asthma can be attributed to occupational factors? Am J Med 1999;107:580-7.

3 Pepys J, Bernstein IL. Historical aspects of occupational asthma. In: Bernstein IL, Chang-Yeung M, Malo JL, et al, eds. Asthma in the workplace, 2nd ed. New York: Marcel Dekker, 1999:5-26.

4 Kogevinas M, Antó JM, Sunyer J, et al. A population based study on occupational asthma in Europe and other industrialised countries. Lancet 1999;353:1750-4.

5 Karjalainen A, Kurppa K, Martikainen R, et al. Work is related to a substantial portion of adult-onset asthma incidence in the Finnish population. Am J Respir Crit Care Med 2001; 164:565-8

6 Zock JP, Kogevinas M, Sunyer J, et al. Asthma risk, cleaning activities and use of specific cleaning products among Spanish indoor cleaners. Scand J Work Environ $2001 ; 27: 76-81$
7 Burney PGJ, Luczynska C, Chinn S, et al. The European Community Respiratory Health Survey. Eur Respir J 1994;7:954-60.

8 Galobardes B, Sunyer J, Antó JM, et al. Effect of the method of administration, mail or telephone, on the validity and reliability of a respiratory health questionnaire. The Spanish centers of the European Asthma Study. J Clin Epidemiol 1998;51:875-81.

9 Meredith S. Reported incidence of occupational asthma in the United Kingdom, 1989-90. J Epidemiol Community Health 1993;47:459-63.

10 Jajosky RAR, Harrison R, Reinish F, et al. Surveillance of work-related asthma in selected US states using surveillance guidelines for state health departments - California, Massachusetts, Michigan and New Jersey, 1993-1995: MMWR surveillance summaries. MMWR 1999;48:1-20.

11 Reinisch F, Harrison RJ, Cussler S, et al. Physician reports of work-related asthma in California, 1993-1996. Am J Ind Med 2001:39:72-83.

12 Bernstein JA, Stauder T, Bernstein DI, et al. A combined respiratory and cutaneous hypersensitivity syndrome induced by work exposure to quaternary amines. J Allergy Clin Immunol 1994;94:257-9.

13 Burge PS, Richardson MN. Occupational asthma due to indirect exposure to lauryl dimethyl benzyl ammonium chloride used in a floor cleaner. Thorax 1994;49:842-3.

14 Quirce S, Gala G, Pérez-Camo I, et al. Irritant-induced asthma: clinical and functional aspects. J Asthma 2000;37:267-74.

15 Wolkoff P, Schneider T, Kildeso J, et al. Risk in cleaning: chemical and physical exposure. Sci Total Environ 1998;215:135-56.

16 Chang-Yeung M, Malo JL. Natural history of occupational asthma. In: Bernstein IL, Chang-Yeung M, Malo JL, et al, eds. Asthma in the workplace, 2nd ed. New York: Marcel Dekker, 1999:129-43.

17 Symanski E, Kupper LL, Rappaport SM. Comprehensive evaluation of long term trends in occupational exposure: part1. Description of the database. Occup Environ Med 1998;55:300-9.

18 Karjalainen A, Martikainen R, Karjalainen J, et al. Excess incidence of asthma among Finnish cleaners employed in different industries. Eur Respir J 2002;19:90-5.

19 Forastiere F, Balmes J, Scarinci M, et al. Occupation, asthma, and chronic respiratory symptoms in a community sample of older women. Am J Respir Crit Care Med 1998;157:1864-70.

20 Fishwick D, Bradshaw LM, D'Souza W, et al. Chronic bronchitis, shortness of breath, and airway obstruction by occupation in New Zealand. Am J Respir Crit Care Med 1997; 156:1440-6.

21 Reilly MJ, Rosenman KD. Use of hospital discharge data for surveillance of chemical-related respiratory disease. Arch Environ Health 1995:50:26-30.

22 Zock JP, Kogevinas M, Sunyer J, et al. For the European Community Respiratory Health Survey. Asthma characteristics in cleaning workers, workers in other risk jobs and office workers. Eur Respir J 2002;20:679-85.

23 Checkoway H, Pearce NE, Crawford-Brown DJ. Issues of study design and analysis. In: Research methods in occupational epidemiology. New York: Oxford University Press, 1989:72-102. 